\title{
WADAI BANJAR RAJA YANG TURUN TAKHTA
}

\author{
Rizki Amalia Afriana, Penta Lestarini, M. Riduan Abdillah \\ STIE Nasional Banjarmasin \\ Email : afriana82@gmail.com
}

\begin{abstract}
Wadai comes from Banjar Language, which means cake, so Wadai Khas Banjar is a typical cake from Banjarmasin City. Wadai Khas Banjar is a mainstay culinary city of Banjarmasin that needs to be maintained, because currently the existence of this Typical Banjar has been eroded by attacks from various kinds of modern cakes that offer a variety of flavors, shapes and preparations, so that the average person if faced with the choice of whether the Wadai Khas Banjar or modern cakes, they prefer modern cakes, because the variations and tastes are very diverse. For this reason, we will strive to help maintain the existence of this Banjar Typical Wadai by conducting activities including the Community Partnership Program. This program is for typical Banjar entrepreneurs who aim to increase the knowledge and competence of Banjar Typical entrepreneurs to solve problems in the field of business management and operating / production aspects in the form of profile and organizational structure, marketing strategies, working capital management and calculation of production costs and product diversity. This activity is planned to be held for 8 months effectively from April to November 2018. The target audience is businessmen and business employees of Wadai Khas Banjar. In the implementation of the activities the materials used consisted of training documents, extension modules, proofs of transactions and raw materials for the typical Banjar Wadai. Approach method for solution to problems in the form of counseling and training, employer mobilization, business management intervention and evaluation of activities of science and technology activities for the community in the form of extension, training and implementation activities in Banjar Wadai Typical business in Banjarmasin Central City District, Banjarmasin in business management and production. The output of this activity is in the form of profile and organizational structure, implementation of new marketing strategies, working capital proposals and calculation of production costs and typical Banjar Wadai products with new flavor variances and forms.
\end{abstract}

Keywords: Community partnership program, Wadai Khas Banjar

\section{PENDAHULUAN}

$$
\text { Usaha Wadai Khas Banjar }
$$

merupakan usaha kuliner yang

merupakan bagian dari ekonomi kreatif

sekaligus sebagai usaha mikro, kecil

dan menengah (UMKM) yang mempunyai kedudukan, potensi dan peranan yang penting dan strategis dalam mewujudkan pembangunan ekonomi nasional seperti peningkatan kesempatan kerja dan pemerataan pendapatan. 
Wadai khas Banjar yang disebut dengan Wadai Banjar 41 Macam, merupakan peninggalan tradisi lama, yang kemudian dilestarikan karena memiliki nilai tradisional sebagai bagian dari budaya orang Banjar. Wadai Banjar 41 Macam ini disajikan kepada para undangan (Banjar: Saruan) pada acara perkawinan yang diselenggarakan oleh keturunan bangsawan dan orang yang memiliki harta berlebih dan merupakan orang Banjar. Selain para acara perkawinan, juga diadakan pada acara kelahiran bayi pertama atau acara khitanan anak laki-laki dari keluarga keturunan hartawan.

Usaha Wadai Khas Banjar ini sangat berpotensi apabila dikembangkan secara maksimal, merupakan produk yang asalnya turun temurun dan mempunyai makna sebagai pelestarian budaya daerah Kalimantan Selatan. Memberikan kontribusi berupa pendapatan bagi pengusaha, menyerap tenaga kerja pada daerah sekitar usaha, serta akan memberikan pendapatan pada pemerintah daerah karena pajak yang dibayarkannya apabila produk ini dipasarkan baik pada pasar lokal, regional maupun nasional.
PERMASALAHAN USAHA WADAI KHAS BANJAR

\section{Identifikasi Permasalahan}

Secara umum UMKM menghadapi 5 permasalahan utama yaitu yang pertama adalah terbatasnya modal dan akses kepada sumber dan pelaku lembaga keuangan, permasalahan yang kedua adalah masih rendahnya kualitas SDM pelaku usaha, yang ketiga adalah kemampuan pemasaran yang terbatas, yang keempat adalah akses informasi usaha yang rendah dan yang kelima adalah belum terjalin dengan baik kemitraan saling menguntungkan antar pelaku usaha (UMKM, Usaha Besar dan BUMN). Demikian juga permasalahan yang dihadapi oleh usaha Wadai Khas Banjar, berdasarkan hasil observasi yang telah dilakukan pada lokasi usaha, yang diidentifikasikan sebagai berikut :

\section{a. Berdasarkan Aspek Produksi / Operasi}

1) Kualitas produk yang belum memiliki standar kualitas.

2) Produk dihasilkan sebagian besar berdasarkan pesanan sehingga produksi tidak berkesinambungan karena belum memiliki tempat 
yang layak untuk

memasarkan usaha.

3) Keterbatasan pengetahuan pemilik usaha dalam menerapkan strategi pemasaran.

4) Keterbatasan SDM dari segi keterampilan membuat wadai agar lebih bervariasi

5) Ketidaktepatan menetapkan harga pokok produksi dari usahanya karena keterbatasan pengetahuan, sehingga biaya produksi ditetapkan berdasarkan perkiraan.

b. Berdasarkan Aspek

\section{Manajemen Usaha}

1) Keterbatasan modal kerja sehingga belum dapat memperkerjakan tenaga kerja, sehingga produksi sangat terbatas. Karena modal yang terbatas menyebabkan alat yang digunakan juga sangat sederhana.

2) Keterbatasan pengetahuan tentang teknologi.

3) Kurangnya varian dalam produk, sehingga produk terbatas jenisnya.
4) Kurangnya informasi khususnya mengenai pangsa pasar, sehingga hanya memasarkan disekitar tempat produksi.

5) Kesulitan dalam mengukur kinerja usaha karena usaha Wadai Khas Banjar tidak melakukan pencatatan transaksi.

6) Keterbatasan dengan akses dengan pihak perbankan dan lembaga keuangan lainnya karena manajemen usaha tidak dilaksanakan dan ketidakmampuan membuat proposal modal kerja.

\section{Prioritas Permasalahan}

Dari sekian banyak permasalahan, dicari akar permasalahan yang sesungguhnya dan disesuaikan juga dengan kemampuan usaha Wadai Khas Banjar dan kepakaran pihak perguruan tinggi yang berupaya berkontribusi untuk mengembangkan usaha Wadai Khas Banjar di kota Banjarmasin. Oleh karena itu masalah yang utama akan diprioritaskan untuk dicarikan solusinya. 
Adapun permasalahan usaha Wadai Khas Banjar yang menjadi prioritas untuk dipelajari dan dicarikan solusinya adalah :

1) Kualitas produk yang belum memiliki standar kualitas.

2) Produk dihasilkan sebagian besar berdasarkan pesanan sehingga produksi tidak berkesinambungan karena belum memiliki tempat yang layak untuk memasarkan usaha.

3) Keterbatasan pengetahuan pemilik usaha dalam menerapkan strategi pemasaran dengan menggunakan teknologi.

4) Keterbatasan SDM dari segi keterampilan membuat wadai agar lebih bervariasi

5) Ketidaktepatan menetapkan harga pokok produksi dari usahanya karena keterbatasan pengetahuan, sehingga biaya produksi ditetapkan berdasarkan perkiraan.
6) Keterbatasan modal kerja sehingga belum dapat memperkerjakan tenaga kerja, sehingga produksi sangat terbatas. Karena modal yang terbatas menyebabkan alat yang digunakan juga sangat sederhana.

7) Kurangnya informasi khususnya mengenai pangsa pasar, sehingga hanya memasarkan disekitar tempat produksi.

8) Keterbatasan dengan akses dengan pihak perbankan dan lembaga keuangan lainnya karena manajemen usaha tidak dilaksanakan dan ketidakmampuan membuat proposal modal kerja.

\section{SOLUSI DAN TARGET LUARAN \\ Berdasarkan rencana kegiatan yang dituangkan dalam kegiatan solusi atas persoalan yang disepakati bersama, maka kegiatan solusi masalah dan terget luaran yang dihasilkan sbb :}

\begin{tabular}{|c|c|c|}
\hline No. & Kegiatan Solusi masalah & TARGET LUARAN \\
\hline \multirow[t]{3}{*}{01} & $\begin{array}{l}\text { 1. Penyuluhan } \\
\text { kewirausahaan }\end{array}$ & $\begin{array}{llr}\text { 1. Sebanyak } & 70 \% \text { pengusaha dan } \\
\text { karyawan } & \text { yang mengikuti } \\
\text { penyuluhan } & \text { memahami aspek }\end{array}$ \\
\hline & 2. Pelatihan kewirausahaan & kewirausahaan. \\
\hline & & $\begin{array}{l}\text { 2. Sebanyak } 70 \% \text { pengusaha dan } \\
\text { karyawan yang mengikuti pelatihan }\end{array}$ \\
\hline
\end{tabular}


mampu meningkatkan kemampuan kewirausahaan.

02. 1. Pelatihan dalam membuat Wadai Khas Banjar yang lebih variatif dari segi bentuk maupun olahan.

2. Pembuatan produk usaha Wadai Khas Banjar yang lebih mampu bersaing dengan kue-kue modern.

03. 1. Penyuluhan perhitungan harga pokok produksi.

2. Pelatihan perhitungan harga pokok produksi.

3. Penerapan perhitungan harga pokok produksi

04. 1. Penyuluhan tentang strategi pemasaran yang efektif dan jelas penerapannya.

2. Pembuatan leaflet atau brosur produk.

05. 1. Penyuluhan tentang laporan laba rugi, neraca, laporan perubahan modal dan manfaat nya

2. Pelatihan pembuatan laporan laba rugi laba, neraca dan laporan perubahan modal.

3. Pembuatan laporan laba rugi, neraca dan laporan perubahan modal

06. 1. Penyuluhan manajemen usaha

tentang

2. Pelatihan dalam manajemen usaha
1. Sebanyak $70 \%$ pengusaha dan karyawan mampu dan trampil dalam membuat Wadai Khas Banjar yang lebih varitif dari segi bentuk maupun olahan.

2. Produk usaha Wadai Khas Banjar yang lebih mampu bersaing dengan kue-kue modern.

1. Sebanyak $70 \%$ pengusaha dan karyawan yang mengikuti penyuluhan memahami perhitungan harga pokok produksi

2. Sebanyak $70 \%$ pengusaha dan karyawan yang mengikuti pelatihan mampu menghitung harga pokok produksi

3. Harga pokok produksi yang standar

1. Sebanyak $70 \%$ peserta penyuluhan memahami tentang strategi pemasaran yang efektif dan jelas penerapannya.

2. Leaflet dan brosur produk

1. Sebanyak $70 \%$ peserta yang mengikuti penyuluhan memahami tentang laporan laba rugi, neraca, perubahan modal dan manfaatnya

2. Sebanyak $70 \%$ peserta yang mengikuti pelatihan mampu dengan baik membuat laporan laba rugi, neraca \& perubahan modal

3. Laporan keuangan berupa neraca, laporan rugi laba dan laporan perubahan modal bagi usaha rabuk haruan

1. Sebanyak $70 \%$ peserta penyuluhan memahami tentang manajemen usaha

2. Sebanyak $70 \%$ peserta pelatihan mampu dan trampil mengelola usahanya 


\begin{tabular}{rlrl}
\hline $\begin{array}{l}\text { 3. Pembuatan profil UMKM dan } \\
\text { struktur organisasi }\end{array}$ & $\begin{array}{l}\text { 3. Profil UMKM dan struktur } \\
\text { organisasi }\end{array}$ \\
07. $\begin{array}{l}\text { 1. Penyuluhan tentang modal } \\
\text { kerja, manajemen modal kerja } \\
\text { dan cara mendapatkan sumber } \\
\text { modal kerja. }\end{array}$ & $\begin{array}{l}\text { 1. Sebanyak 70 \% peserta penyuluhan } \\
\text { memahami tentang modal kerja dan } \\
\text { prosedur mendapatkan modal kerja }\end{array}$ \\
$\begin{array}{l}\text { 2. Pelatihan pembuatan } \\
\text { proposal untuk mendapatkan } \\
\text { modal kerja. }\end{array}$ & 2. Proposal Modal Kerja & \\
$\begin{array}{l}\text { 3. Pengajuan proposal untuk } \\
\text { mendapatkan modal kerja pada } \\
\text { pihak pemerintah, lembaga } \\
\text { keuangan atau BUMN }\end{array}$ & 3. Besarnya modal kerja yang \\
diperoleh & & \\
\end{tabular}

\section{METODE PELAKSANAAN}

\section{Metode}

\section{Pendekatan}

\section{Solusi}

Permasalahan

Metode pendekatan solusi permasalahan yang ditawarkan untuk mendukung realisasi program kemitraan masyarakat sebagai berikut :

a. Penyuluhan dan pelatihan bagi pemilik usaha Wadai Khas Banjar

Metode penyuluhan bertujuan untuk memberikan wawasan kepada pemilik usaha wadai khas Banjar tentang laporan keuangan, manajemen usaha, manajemen pemasaran dan modal kerja, manajemen sumber daya manusia dan modifikasi produk.

b. Mobilisasi pengusaha Wadai Khas Banjar

Dalam metode ini para pengusaha dimobilisasi untuk menerapkan pengetahuan, sistem atau metode yang telah mereka peroleh dari penyuluhan dan pelatihan.

\section{c. Intervensi dalam manajemen usaha.}

Metode intervensi dalam manajemen usaha bertujuan memberikan wawasan secara umum tentang laporan keuangan, manajemen pemasaran dan modifikasi produk yang telah dilakukan oleh pengusaha, mengevaluasi strategi pemasaran dan laporan keuangan yang diterapkan dan produk yang dihasilkan, dan memperkenalkan strategi pemasaran yang efektif produk yang telah dimodifikasi serta memberikan akses untuk menjalin kerjasama dengan pihak lain. 


\section{d. Evaluasi Hasil Kegiatan.}

Pada setiap akhir kegiatan penyuluhan, pelatihan maupun pelaksanaan setiap materi, diadakan evaluasi terhadap hasil kegiatan dengan metode yang relevan, sehingga keberhasilan setiap materi yang disajikan dapat terukur. Misalnya untuk pemahaman maka diberikan pertanyaan dimana jawabannya menggambarkan bahwa peserta mengetahui dan memahami materi tersebut. Untuk kegiatan pelatihan maka hasilnya terukur dari kemampuan mempraktekan materi pelatihan. Sebagai contoh pelatihan laporan keuangan, dikatakan pelatihan tersebut berhasil bila peserta pelatihan mampu membuat laporan keuangan.

\section{Rencana Kegiatan sebagai Solusi Permasalahan}

Dalam upaya memberikan solusi terhadap permasalahan yang dihadapi oleh usaha Wadai Khas Banjar,maka kegiatan yang akan dilakukan sbb :

Masalah : Keterbatasan sumber daya manusia dari segi keterampilan, pendidikan dan pelatihan.

\section{Solusi :}

$\checkmark$ Penyuluhan tentang kewirausahaan

$\checkmark$ Pelatihan tentang kewirausahaan

Masalah : Kurangnya keragaman jenis \& modifikasi produk

\section{Solusi :}

$\checkmark$ Pelatihan dalam meragamkan dan memodifikasi produk yang dihasilkan.

$\checkmark$ Pembuatan produk usaha Wadai Khas Banjar yang lebih kompetitif.

Masalah : Ketidaktepatan menetapkan harga pokok produksi dari usahanya karena keterbatasan pengetahuan, sehingga biaya produksi ditetapkan berdasarkan perkiraan.

\section{Solusi :}

$\checkmark \quad$ Penyuluhan perhitungan HPP

$\checkmark$ Pelatihan perhitungan HPP

$\checkmark$ Penerapan perhitungan HPP

\section{Masalah :}

Keterbatasan pengetahuan tentang teknologi dan kurangnya informasi khususnya mengenai pasar. Produk hanya dijual di toko di sekitar tempat tinggal. Secara umum pembeli biasanya datang langsung membeli kerumah.

\section{Solusi :}




$\begin{array}{ll}\checkmark & \text { Penyuluhan tentang strategi } \\ & \text { pemasaran } \\ \checkmark & \text { Pelatihan pemasaran produk dgn } \\ & \text { strategi yang efektif } \\ \checkmark & \text { Pembuatan leaflet atau brosur } \\ & \text { produk }\end{array}$

Masalah : Kesulitan dalam mengukur kinerja usaha karena usaha pengolahan wadai khas Banjar tidak melakukan pencatatan transaksi.

\section{Solusi :}

$\checkmark$ Penyuluhan tentang laporan laba rugi, neraca, laporan perubahan modal dan manfaat nya

$\checkmark$ Pelatihan pembuatan laporan laba rugi laba, neraca dan laporan perubahan modal.

$\checkmark$ Pembuatan laporan laba rugi, neraca dan laporan perubahan modal

Masalah : Keterbatasan dengan akses dengan pihak perbankan dan lembaga keuangan lainnya karena manajemen usaha tidak dilaksanakan dan ketidakmampuan membuat proposal modal kerja.
Penyuluhan tentang modal kerja, manajemen modal kerja dan cara mendapatkan sumber modal kerja.

$\checkmark$ Pelatihan pembuatan proposal utk mendapatkan modal kerja.

$\checkmark$ Pengajuan proposal untuk mendapatkan modal kerja pada pihak pemerintah, lembaga keuangan atau BUMN

Masalah : Manajemen usaha sistem kekeluargaan

\section{Solusi :}

$\checkmark$ Penyuluhan tentang manajemen usaha

$\checkmark$ Pelatihan dalam manajemen usaha

$\checkmark$ Pembuatan profil UKM dan struktur organisasi

Pengusaha Wadai Khas Banjar di Kota Banjarmasin sangat antusias untuk mendukung kegiatan ini yang ditunjukkan kesediaan bekerjasama dan menjadi obyek kegiatan serta menyediakan bahan dan peralatan serta tempat untuk kegiatan. Untuk tehnis pelaksanaan kegiatan telah dirundingkan secara kekeluargaan sehingga menguntungkan bagi kedua belah pihak, yang tidak akan mengganggu kegiatan pengusaha

\section{Solusi :}


pengolahan Wadai Khas Banjar maupun pihak penyelenggara program.

\section{HASIL YANG DICAPAI}

Pengabdian dengan skim

Program Kemitraan Masyarakat ini telah dilaksanakan sejak bulan Mei 2018 . Adapun kegiatan-kegiatan yang telah dilakukan adalah sebagai berikut :

1. Sosialisasi akan diadakannya kegiatan pengabdian PKM pada kelompok usaha wadai khas Banjar di Kecamatan Banjarmasin Tengah.

2. Peninjauan lokasi tempat usaha pembuatan wadai khas Banjar pada kedua mitra pengabdian.

3. Pelaksanaan Kegiatan Bazar Ramadhan sebagai awal untuk mengetahui bagaimana respon konsumen terhadap Wadai Khas Banjar.

4. Peninjauan tempat untuk kegiatan penyuluhan dan pelatihan kepada mitra pengabdian yang berlokasi di Hotel Roditha Banjarmasin.

5. Identifikasi alat-alat yang dibutuhkan oleh mitra pengabdian.

6. Mempersiapkan kegiatan penyuluhan dan pelatihan kepada mitra pengabdian tentang kewirausahaan, strategi pemasaran, manajemen usaha dan yang berkaitan dengan pengelolaan keuangan.

7. Melaksanakan kegiatan penyuluhan dan pelatihan untuk mitra pengusaha wadai khas Banjar :

a. Penyuluhan tentang kewirausahaan : $\mathrm{Hj}$. Diana Hayati, SE, MM

b. Pelatihan tentang kewirausahaan : Dewi Setiawati, SE, MM.

c. Penyuluhan tentang strategi pemasaran : Drs. Masrifani, MM.

d. Pelatihan tentang strategi pemasaran : Dr. Ni Nyoman Suarniki, MM.

e. Pemberian alat dan modal kerja yang dibutuhkan oleh mitra pengabdian untuk pengembangan pembuatan wadai khas Banjar.

f. Penyuluhan dan Pelatihan tentang manajemen usaha : Ferly Setiawan, SE, MM.

g. Penyuluhan dan Pelatihan tentang Modal Kerja dan Pembuatan Proposal untuk mendapatkan modal kerja : Ruslinda Agustina, SE, MSA.

h. Penyuluhan dan Pelatihan tentang Harga Pokok Produksi : Yacub Sarhindi, SE. 
i. Penyuluhan dan Pelatihan tentang Laporan L/R : Indra Saputra, SE, M. Si

j. Penyuluhan dan Pelatihan tentang UMKM : Drs. $\mathrm{H}$. Mohdari, M. Si

8. Melaksanakan kegiatan pelatihan dan praktek mengolah Wadai Khas Banjar oleh Narasumber yang ahli dalam pengolahan Wadai Khas Banjar.

9. Merancang strategi pemasaran yang tepat untuk dapat diterapkan oleh kedua mitra.

10. Merancang proposal untuk mendapatkan modal kerja untuk kedua mitra

11. Membuat laporan keuangan untuk mengevaluasi kinerja keuangan selama ini sehingga dapat diperbaiki kedepannya.

\section{KESIMPULAN}

Pengabdian PKM pada pengusaha Wadai Khas Banjar di Kecamatan Banjarmasin Tengah Kota Banjarmasin telah dapat dijalankan dengan baik dan tanpa halangan yang berarti. Dengan kerjasama tim pengabdian yang baik dan peran serta aktif dari penyuluh/narasumber dan panitia dalam kegiatan pengabdian ini maka semuanya telah berjalan sesuai yang diharapkan dan semoga dapat memberikan manfaat bagi mitra pengabdian masyarakat dalam keberlanjutan usaha wadai khas Banjar yang dikelola mitra pengabdian saat ini.

Pengabdian yang kami lakukan ini telah sampai pada tahapan dilaksanakannya kegiatan penyuluhan dan pelatihan tentang kewirausahaan, strategi pemasaran, manajemen usaha dan hal-hal yang berkaitan dengan pengelolaan keuangan dan untuk kegiatan pelatihan yang terakhir telah dilaksanakan kegiatan praktek membuat Wadai Khas Banjar dalam rangka untuk memberikan pencerahan kepada kedua mitra untuk dapat lebih berkreasi dan memperbaiki kualitas dari segi rasa maupun bentuk supaya dapat lebih bersaing dengan kue-kue modern saat ini.

\section{DAFTAR PUSTAKA}

Badan Pusat Statistik Indonesia. 2012 Statistik Ekonomi Kreatif. Jakarta. PPKI. 2012. Buku Program PPKI 2012. Jakarta

Kumara Sadana Putra,Meneropong Industri Kreatif Indonesia dari Pameran Produk Kreatif Indonesia (PPKI), 29 Nopember 2012 